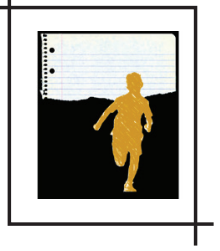

\title{
ENCONTROS E DESENCONTROS NA PASSAGEM DA EDUCAÇÃO INFANTIL PARA O ENSINO FUNDAMENTAL
}

\author{
Kelen A. Galvão Pinheiro* \\ Filomena M. de Arruda Monteiro**
}

\begin{abstract}
Resumo: Este artigo é resultante de pesquisa de cunho teórico em que se analisa a passagem das crianças da educação infantil para o ensino fundamental. Objetiva-se expandir a compreensão principalmente dos conceitos de infância, criança, entre outros referenciados pela educação infantil para o ensino fundamental. Na atual conjuntura, é imprescindivel que se pense e reflita sobre o que para nós é a infância, a criança e seu papel transformador no mundo que enfrenta. Concomitantemente, trataremos do que os documentos legais dizem sobre isso e qual é o lugar da infância nos primeiros anos do ensino fundamental. Convidamos o leitor a lançar um novo olhar sobre a infância e as ações que ela nos permite realizar. Embasamo-nos nos estudos de Richter (2008), Peripolli, Pasuch e Zoia (2018), Corsaro (2011), Kramer (2006), Bueno (2018), Brasil (2018a, 2018b), Oliveira-Formosinho (2008), entre outros.
\end{abstract}

Palavras-chave: Infância. Criança. Vivências. Experiências. Passagem da educação infantil para o ensino fundamental.

\section{INTRODUÇÃO}

"Imaginem um lugar onde a infância pudesse habitar e ser habitada pelo mundo... Pudesse ser sua criadora e a própria criação. Um lugar onde as coisas ganham sentido pela mágica da existência. Um lugar repleto de olhares, formas, gestos, cores, sentires, texturas, jogos e abraços... Afeto! Bem, é para esse lugar que eu me imagino indo todos os dias e a cada dia que entro em uma escola" (SEVERINO ANTONIO apud BUENO, 2018, p. 10).

Este texto nasce da necessidade e da angústia vivenciada pela primeira autora durante o período de pesquisa do mestrado em Educação, numa turma de primeiro ano do ensino

\footnotetext{
* Graduada em Pedagogia e Pós-graduada em Psicopedagogia. Mestranda pelo Programa de Pós-Graduação em Educação na UFMT/ Cuiabá. E-mail: galvakelly@gmail.com

** Pós-Doutoura em Educação e Prof. O Orientadora no Programa de Pós-Graduação em Educação na UFMT/ Cuiabá.
} 
fundamental de uma escola da rede municipal de Sinop, no estado de Mato Grosso. As situações vivenciadas tornaram a experiência vivida nesse periodo única e riquíssima de significado tanto na minha vida pessoal quanto na profissional. Tudo o que vi e vivi teve grande "afetamento", do verbo "afetar", em minha prática pedagógica e na resistência de uma luta de enfrentamento das políticas públicas para uma educação de qualidade na primeira infância.

É importante ressaltar que, por mais que as angústias que me levaram a pensar em algumas inquietações e escrevê-las neste texto tenham borbulhado no período de pesquisa do mestrado, elas não foram resultados da pesquisa, nem do objetivo ou do problema que me impulsionou na continuação da formação na vida acadêmica. Durante a realização da pesquisa, surgem inúmeras outras dúvidas que dariam inúmeras outras pesquisas; então, essa foi uma delas.

Como professora de crianças pequenas da educação infantil, estar numa sala de primeiro ano sempre foi algo desejado, para conhecer a realidade dessa turma e seu dia a dia. Na pesquisa do mestrado, tive a oportunidade de vivenciar essa experiência e foi muito importante, pois me permiti estar num lugar novo lançando um novo olhar, o olhar de pesquisadora.

Felizmente podemos dizer que as pesquisas na área da infância têm ganhado muitas contribuições. Quando buscamos os sites científicos de artigos, dissertações e teses, encontramos um leque muito abrangente relacionado a essa área de estudos, com os mais variados temas, o que nos possibilita ter maior clareza e conhecimento da particularidade dessa fase da vida que é tão peculiar e única: a infância.

É válido lembrar que as crianças que iniciam sua vida escolar no primeiro ano do ensino fundamental são ainda muito pequenas e estão dentro do período determinado legalmente pelo Estatuto da Criança e do Adolescente (ECA) de infância. De acordo com o ECA, Lei n. 8.069, de 13 de julho de 1990, o período que abrange a fase da infância vai de 0 a 12 anos de idade: "Art. $2^{\circ}$ Considera-se criança, para os efeitos desta Lei, a pessoa até doze anos de idade incompletos, e adolescente aquela entre doze e dezoito anos de idade".

Isso posto, vamos adentrar esse mundo da infância e de suas possibilidades, em que as crianças têm oportunidades de rir e chorar, de correr e andar ao seu ritmo e ao seu tempo, tempo que passa tão rapidamente que chega a deixar saudades, cheiros e sabores de coisas que viveram, experimentaram e exploraram. Vamos esboçar algumas reflexões e provocar pensamentos: afinal, por que não se vive com intensidade a infância nas séries iniciais? Qual é o lugar da infância nos primeiros anos do ensino fundamental? 0 que fazer com a ânsia de brincar, explorar, conhecer, investigar, falar, cantar e se movimentar que a criança traz impregnada em seu corpo da educação infantil? Esse é um convite a repensar quais são os encontros e desencontros que as crianças têm vivido nos primeiros anos da vida escolar, no ensino fundamental. 


\section{"INFANCIAR", UM MODO DE PENSAR A INFÂNCIA}

Se nos atermos a compreender o significado da palavra "infância", ela é um substantivo feminino. Etimologicamente, a palavra "infância" tem origem no latim infantia, do verbo fari $=$ falar, em que fan $=$ falante e in constitui a negação do verbo. Portanto, infans refere-se ao indivíduo que ainda não é capaz de falar.

Historicamente, a infância ficou registrada como inexistente durante um longo período. As primeiras demonstrações tímidas da existência e do reconhecimento das crianças, que ainda eram diferenciadas dos adultos apenas pelo seu tamanho, surgiram nas artes medievais por meio das pinturas religiosas feitas na Bíblia, como descreve Ariès (1981, p. 50): "Até por volta do século XII, a arte medieval desconhecia a infância ou não tentava representá-la". No segundo capítulo da obra História social da criança e da familia, Ariès (1981) se remete a várias obras de arte religiosas em que a figura de um ser menor compunha as cenas. A incapacidade das crianças ficou marcada nos livros. Alguns historiadores descrevem-nas como anjos, já que a figura delas estava intimamente ligada à pureza e à inocência das imagens angelicais pintadas nos quadros que ornamentavam as casas e igrejas da época. As crianças morriam em grande quantidade e ainda bem pequenas. Considerava esse fato normal, pois era uma consequência direta e inevitável da demografia da época.

Não existiam brinquedos, roupas e atividades de lazer que fossem pensados para as crianças; elas simplesmente existiam, e algumas nem eram notadas, mas estavam ali. Desde então, ao longo dos anos não somente a personificação da figura infantil foi ganhando forma, mas também a sua existência foi considerada como pessoa, integrante de um grupo social, alguém que existe e precisa de cuidados especiais.

Corazza (2002, p. 81) nos auxilia quando afirma o seguinte:

As crianças são as grandes ausentes da história simplesmente porque, no chamado "passado" - da Antiguidade à Idade Média -, não existia esse objeto discursivo a que chamamos "infância", nem essa figura social e cultural chamada "criança", já que o dispositivo de infantilidade não operava para especificamente criar o infantil [...].

Alguns olhares foram lançados sobre a criança, e, aos poucos, ela foi sendo vista não apenas como um adulto em miniatura, mas também como um ser humano capaz de construir seu mundo, não deixando de ser pura e viver intensamente com seus medos, angústias, alegrias e tristezas de maneira intensa e significativa. Walter Benjamin (1984, p. 11) já descrevia a criança sob esse olhar:

[...] não é uma miniatura do cosmos adulto; bem ao contrário, um ser humano de pouca idade que constrói seu próprio universo, capaz de incluir lances de pureza e ingenuidade, 
sem eliminar, todavia, a agressividade, resistência, perversidade, humor, vontade de domínio e de mando.

Souza (2011 apud RODRIGUES; BORGES; SILVA, 2014, p. 271-272) nos chama a atenção para o fato de que,

[...] a partir dos processos histórico-sociais e das relevantes contribuições de diversas áreas do conhecimento, hoje, a criança é vista como sujeito concreto que integra uma categoria geracional; uma construção social que, com o passar do tempo, se transforma, variando entre grupos sociais e étnicos dentro de qualquer sociedade. Essas formas diferenciadas de se ver e de tratar esses seres de pouca idade é o que chamamos de "infância".

A partir dessas contribuições, podemos concordar com Souza (2011 apud RODRIGUES; BORGES; SILVA, 2014, p. 272) quando afirma o seguinte:

Infância é uma forma de ser criança, ou melhor, as formas, pois, a partir dessa definição, não teremos mais uma única infância e, sim, infâncias. Essas formas de se ver e conceber os diversos tipos de infância fazem parte de um processo histórico-cultural que foi sendo construído e modificado em diferentes tempos, espaços e sociedades.

Para Kramer (2006, p. 17), levando em consideração tais aspectos em análise, a infância não é algo tão intrínseco aos seres humanos, pois, segundo ela, a infância não é um produto da "natureza", mas uma construção histórica, com a finalidade de possibilitar "a consciência da particularidade infantil, ou seja, aquilo que distingue a criança do adulto [...]".

Corsaro $(2011$, p. 15) nos ajuda a compreender melhor ao apontar que
[...] as crianças são agentes sociais, ativos e criativos [...] a infância - esse periodo social- mente construído em que as crianças vivem suas vidas - é uma forma estrutural [...] uma categoria ou uma parte da sociedade, com classes sociais e grupos de idade. Nesse sentido as crianças são membros e operadores de suas infâncias. Para as próprias crianças, a infân- cia é um período temporário.

Sarmento (2004 apud RODRIGUES; BORGES; SILVA, 2014, p. 273) apresenta uma citação que nos ajuda a situar o lugar da infância e da criança atualmente na sociedade, quando ressalta que:

0 olhar que temos hoje da infância, da criança, do aluno não é o mesmo de séculos ou décadas atrás, pois o mesmo sofreu processos que levam a transformações que direcionam 
a uma nova visão. Todas essas mudanças direcionam a uma nova forma de ver as crianças. Dentre as transformações que ocorreram nos últimos vinte ou trinta anos talvez a mais importante seja aquela em que a criança começa não apenas a ser vista, mas também "ouvida", sendo percebida como agente participativo da sociedade em que vive.

Nessa mesma perspectiva, em 2009, a partir da Resolução n. 05, de 17 de dezembro, o governo federal fixa um documento histórico brasileiro, no qual, pela primeira vez, há uma concepção de criança registrada documentalmente, a fim de que as escolas se orientem e pensem suas ações e seu currículo à luz dessa concepção. De acordo com as Diretrizes Curriculares Nacionais para a Educação Infantil (DCNEI), a criança é:

\begin{abstract}
Sujeito histórico e de direitos que, nas interações, relações e práticas cotidianas que vivencia, constrói sua identidade pessoal e coletiva, brinca, imagina, fantasia, deseja, aprende, observa, experimenta, narra, questiona e constrói sentidos sobre a natureza e a sociedade, produzindo cultura (BRASIL, 2010, p. 10).
\end{abstract}

Até chegarmos a esse momento, foram longos anos de negação. Não que hoje todos considerem a criança como ela realmente anseie ser vista, mas muitos direitos foram conquistados durante a história da humanidade, inclusive o conceito de infância.

Pode-se dizer que chega a ser contraditório que o significado da palavra infância, descrito no início deste texto, seja ligado à incapacidade de fazer algo, ainda que seja a fala, que como sabemos é inicialmente adquirida aproximadamente dois anos após o nascimento do bebê. À criança é confiado o direito de fazer tudo. Ela é capaz de tudo.

Perceber e considerar a infância um momento extremamente importante da vida humana e de seu desenvolvimento social é fundamental. De acordo com o Instituto Brasileiro de Geografia e Estatística (IBGE) na matéria intitulada "Expectativa de vida dos brasileiros aumenta 3 meses e chega a 76,6 anos em 2019", realizada em novembro de 2020, uma pessoa nascida no Brasil em 2019 tinha a expectativa de viver, em média, até os 76,6 anos. Se compararmos com o tempo que o ser humano tem disponível para ser criança (que, segundo o ECA, é de 12 anos), são pouquíssimos anos para desvendar, inventar, reinventar, pintar, falar, andar, imaginar, fantasiar, experimentar, sonhar, observar, narrar, contar, amar, cantar, chorar, gritar, desejar, melecar, nadar, saltitar, brincar. Todas essas ações desempenhadas pelas crianças são verbos regulares que, uma vez classificados, estão no infinitivo.

Pensando em todas essas ações inerentes ao ser criança, nas relações que ela pode estabelecer com o meio, com o outro e consigo mesma, e na fase da vida dedicada a esse momento, podemos dizer que a palavra infância poderia estar ligada diretamente com todas essas ações capazes de ser realizadas pelas crianças e até ousaríamos mudar sua classificação gramatical: passaria então a ser um verbo (já que ele contém a noção de ação) no infinitivo "infanciar". 
"Infanciar" significa a ação da criança na infância. Ação tal, que consiste em viver intensamente um momento da vida repleto de significações e com inúmeras ações, relações, descobertas, estreitamentos e pensamentos que promovem o desejo de querer mover e se mover em meio a esse grupo social que precisa ser escutado e percebido como agente participativo na sociedade em que vive.

Bueno (2018) nos apresenta um texto lindíssimo, cheio de reflexões e possibilidades de pensar a infância não apenas como um momento e uma fase da vida, mas também como uma infância cheia de "ar". 0 ar que nos impulsiona a viver diariamente, o ar que é responsável pelas idas e vindas da natureza numa tarde ensolarada cheia de folhas voando pelo céu. 0 ar que corre como vento e faz colorir o céu com as voltas e reviravoltas das pipas coloridas e cheias de formas engraçadas. 0 ar que nos enche o pulmão e nos convida a movimentar essa máquina chamada corpo, que tantos desejos nos leva a realizar, que tantas relações nos faz inspirar; enfim, uma infância que possibilita transformar tudo que acontece em experiências, cheia de possibilidades, oportunidades, prazeres e desprazeres; enfim, uma infância cheia de vida. Segundo Bueno (2018, p. 16):

\begin{abstract}
A infância é o lugar da VIDA! Sim, a vida acontecendo no instante presente. Com todos os sentimentos que ela pode nos oferecer. [...] podemos propor uma infância como o lugar da descoberta, mas da descoberta que a vida é intensa em seus sentires. Infância como o lugar das incertezas. Sim, porque crescer, amadurecer, envelhecer nos dá medo, nos causa insegurança. Não sabemos o que vem a seguir, não sabemos o que está adiante. Ela nos ensina que o caminho vale mais do que a chegada. E não é assim que acontece com as crianças? Quem já presenciou uma criança preparando sua brincadeira? Arruma tudo direitinho, monta as peças e bonecos com os quais vai brincar em sua história e, na hora de brincar, descobre que a brincadeira foi muito mais a preparação!
\end{abstract}

Caminhamos com essa possibilidade de movimentar e evidenciar a infância, de "infanciar" essa fase da vida que é tão rica e que o caminho trilhado nessa fase, como enfatiza Bueno (2018), seja a preparação para uma vida cheia de desafios e conquistas, cheia de encontros e desencontros, porém com segurança, garra e determinação para que no final tudo fique bem.

\title{
QUAL É O LUGAR DA INFÂNCIA NOS PRIMEIROS ANOS DO ENSINO FUNDAMENTAL?
}

Como já mencionado, este texto nasce das tantas angústias vivenciadas durante a pesquisa de mestrado no ano de 2020, numa turma de primeiro ano do ensino fundamental, numa escola da rede pública da cidade de Sinop, em Mato Grosso. Sinop está localizada a 500 
quilômetros da capital Cuiabá e se destaca no cenário estadual por ser um grande centro econômico do agronegócio e um polo estudantil. Dada essa situação, a cidade cresce a passos largos, e é comum as escolas receberem inúmeras crianças novas, principalmente as de educação infantil.

A pesquisa começou no ano letivo e foi realizada diariamente durante dois meses, sendo interrompida apenas pela paralisação das aulas devido à pandemia do coronavírus. Nesse periodo, muitos momentos foram marcantes e fundamentais para melhor compreensão da dinâmica de uma turma de primeiro ano. A turma era composta por 25 crianças, oriundas da educação infantil do município, de outras cidades e outros estados, e por outras que nunca haviam frequentado a escola. Muitas meninas compunham a turma, na verdade a maioria, e um professor era responsável por ela.

0 professor era muito atencioso e demonstrava carinho e preocupação com todas as crianças. Foi receptivo nos primeiros dias de aula com as crianças e dispensava um tempo na porta da sala para conversar com os pais que se dirigiam a ele. Em sala, sempre conversava com as crianças sobre tudo o que iria acontecer e diariamente explicava-Ihes que não estavam mais na educação infantil e nem em suas casas; agora elas deviam se comportar de maneira diferente e obedecer às regras da escola.

No primeiro dia de aula, as crianças ficaram muito quietas, e pouco barulho se ouvia na sala durante a aula. A partir do segundo dia, começaram a restabelecer relações com os colegas que vieram da mesma escola no ano anterior e, após o terceiro dia, já procuravam agrupar-se conforme suas preferências e identificações.

Desde então, a brincadeira corria solta dentro da sala de aula, porém "secretamente", pois o professor não poderia saber. Alguns grupinhos já começavam a se formar, tanto de meninas quanto de meninos, porém o deles com menos componentes. Durante as quatro horas de aula, podia-se perceber nitidamente a intencionalidade da brincadeira acontecendo no decorrer da aula. Tudo virava brincadeira.

A liderança do grupo feminino era uma menina muito esperta e ativa e sempre se declarava a líder das brincadeiras. Ao chegar à sala, já distribuía um papel pequeno com letrinhas escritas para as meninas que faziam parte do "grupinho" (assim chamado por ela) e ali ditava as regras da brincadeira a aula inteira. Elas eram mamãe, filhinhas e babá. Diretora, professora e alunas. Todas as amigas iam para a festa (hora do recreio), entre outras brincadeiras. As meninas que não participavam do grupinho se relacionavam entre si, nas carteiras que, na primeira semana, estavam dispostas em duplas. Tudo muito "escondido" para o "prof" não brigar.

Os meninos, por sua vez, não tinham um líder declarado, mais já se relacionavam entre si também. E durante a aula, não conseguiam ter a mesma agilidade nas brincadeiras como o grupo das meninas, mas sempre estavam brincando e conversando uns com os outros. Alguns meninos eram muito tímidos e ficavam mais calados, e às vezes davam risada com alguma travessura. 
Após a primeira semana, o professor reorganizou a sala em fileiras tradicionais. Contudo, isso não impediu que a brincadeira acontecesse, não com tanto sucesso como antes, mas passou a ficar mais evidente porque agora as meninas tinham que levantar com mais frequência das suas cadeiras para irem até as outras e muitas vezes ficavam bastante tempo viradas para trás conversando umas com as outras. As meninas do "grupinho" sempre davam um jeito de sentar perto umas das outras, até que o professor, ao perceber a movimentação constante, voltasse a separá-las e a ditar os lugares em que deveriam se sentar.

Com os meninos foi a mesma situação, e eles usavam a imaginação para saciar sua vontade de brincar e de se movimentar. Os lápis viravam baquetas de bateria que batiam na mesa, tirando um som até que bem compassado. Os aviões coloridos passaram a voar na sala com mais frequência, pois os lápis de cor serviam para ir até uma mesinha e voltar ligando e desligando suas turbinas. Um garoto muito talentoso fazia desenhos de personagens animados e instigava a curiosidade dos demais, que começaram a desenhar também, e eles expunham seus feitos para os outros e no final da aula trocavam os desenhos.

A tesoura e a cola foram boas aliadas nesse momento em que a criatividade estava aflorada. Os meninos cortavam papel para fazer diversos desenhos: monstrinhos ganhavam formas, embarcações surgiam navegando mar afora e os aviões começavam a ganhar outros céus, até chegarem ao céu do professor, no qual perdiam a força de voar. Nesses momentos, o professor se posicionava intolerante, e a turma se aquietava. Um silêncio pairava no ar, mas os olhares saltitavam na mesma intensidade.

Esses breves relatos de alguns dias com essa turma nos permitem tecer inúmeras reflexões, porém a pretendida aqui é perceber qual lugar está permitido à infância no ensino fundamental. Quando as crianças podem ser crianças? Quais vivências as crianças têm no ensino fundamental que Ihes permitem continuar potencializando suas máximas de expressões, criatividade, resoluções de problemas, leitura de mundo?

A passagem da educação infantil para o ensino fundamental sempre foi uma preocupação das famílias e principalmente dos educadores, tanto da educação infantil como do ensino fundamental, ambos com suas particularidades, porém sempre existiu uma discussão muito forte sobre o grande distanciamento das duas etapas de ensino.

Desde a homologação da Lei Federal n. 11.274/2006, que ampliou o ensino fundamental para nove anos, essa discussão ganha destaque no cenário educacional, por inúmeros fatores, como a acentuação desse distanciamento cada vez mais presente em ambas as etapas e a diminuição da idade com que as crianças iniciam agora o ensino fundamental.

Vale ressaltar que há mais de duas décadas o governo federal já esboçava certa preocupação com esse momento de passagem das crianças. 0 Referencial Curricular Nacional para a Educação Infantil (BRASIL, 1998, p. 84) indicava cuidado e preconizava um trabalho a ser desenvolvido desde as turmas da pré-escola, para que a criança fosse capaz de compreender que esse processo seria necessário, porém ocorreria de forma natural: 
A passagem da educação infantil para o ensino fundamental representa um marco significativo para a criança podendo criar ansiedades e insegurança. 0 professor da educação infantil deve considerar esse fato desde o início do ano, estando disponivel e atento para as questões e atitudes que as crianças possam manifestar. Tais preocupações podem ser aproveitadas para a realização de projetos que envolvam visitas a escolas de ensino fundamental; entrevistas com professores e alunos; programar um dia de permanência em uma classe de primeira série. É interessante fazer um ritual de despedida, marcando para as crianças este momento de passagem com um evento significativo. Essas ações ajudam a desenvolver uma disposição positiva frente às futuras mudanças demonstrando que, apesar das perdas, há também crescimento.

Anos mais tarde, os documentos emitidos pelo governo federal reafirmam que, na passagem da educação infantil para o ensino fundamental, não deve haver ruptura, muito pelo contrário, a continuação e ampliação das aprendizagens devem ser características desse momento, assegurando que "a transição da Educação Infantil para o Ensino Fundamental ocorra de forma mais natural possível, não provocando nas crianças rupturas e impactos negativos no seu processo de escolarização" (BRASIL, 2004, p. 21).

As DCNEI dedicaram um parágrafo em seu texto, no qual também deixam explícito que

[...] na transição para o Ensino Fundamental a proposta pedagógica deve prever formas para garantir a continuidade no processo de aprendizagem e desenvolvimento das crianças, respeitando as especificidades etárias, sem antecipação de conteúdos que serão trabalhados no Ensino Fundamental (BRASIL, 2010, p. 30).

Entre as pesquisas documentais, não poderia faltar o que nos diz o Documento de referência curricular para Mato Grosso: educação infantil (BRASIL, 2018a). No caderno referente à educação infantil, o texto esboça a preocupação com o momento de transição e coaduna com a ideia de que esse momento seja visto como uma continuidade de ações entre as duas etapas, respeitando as particularidades da infância.

Deste modo, destaca-se a necessidade de o Ensino Fundamental estabelecer garantias de continuidade fundadas em princípios que respeitem as particularidades da Infância, intermediados por um currículo sólido, articulado e em sintonia com a Educação Infantil. Diante disso, compreende-se que o momento em que a criança deixa a pré-escola para ingressar no EF, se faz necessário unir esforços entre ambas as etapas, para que o foco seja a busca por estratégias que supram as necessidades da criança no período da infância, empregando melhor o tempo e o espaço destinados a sua aprendizagem e desenvolvimento, como também a qualificação dos professores, sobretudo com propostas pedagógicas consistentes e adequadas a esse público infantil (BRASIL, 2018a, p. 21). 
0 caderno de orientações referente aos anos iniciais traz, logo em seu primeiro texto e em concordância com o caderno anterior, a preocupação com a passagem das crianças para o ensino fundamental, sugerindo que esse momento seja pensado em parceria pelas duas etapas, de maneira colaborativa, a partir de ações que favoreçam essa transição. Além disso, enfatiza que a brincadeira seja valorizada e vista como ponto de convergência pelos docentes para alcançar esse objetivo comum. As múltiplas linguagens também são foco desse texto, pois evidenciam o papel fundamental da brincadeira, dos jogos, da ludicidade, da dramatização, entre outras linguagens:

0 trabalho com as múltiplas linguagens pode assegurar a experiência da infância com a brincadeira, a dança, a gestualidade, o canto, a recitação, a dramatização, dentre tantas outras linguagens que podem ser experimentadas pelas crianças na Educação Infantil e também no Ensino Fundamental (BRASIL, 2018b, p. 5).

Nesse orientativo, é notória a preocupação com a continuidade das interações e brincadeiras (eixos centrais do currículo da educação infantil) como forma de aprendizagem e organização do trabalho a ser desenvolvido.

É possivel perceber que as crianças, durante uma brincadeira, agem e pensam de maneira mais complexa do que em outras atividades. Na impossibilidade de agir como adultos, criam circunstâncias fantasiosas, comportando-se de forma parecida. Esses momentos lúdicos, organizados a partir de regras próprias ao ato de brincar, traduzem situações antecipatórias que favorecem a consolidação do pensamento abstrato (BRASIL, 2018b, p. 5).

0 Documento de referência curricular para Mato Grosso: ensino fundamental - anos iniciais (BRASIL, 2018b, p. 5) corrobora esse pensamento ao afirmar o seguinte:

Por meio da interação e das brincadeiras a criança se expressa, se movimenta, sente e explora seu ambiente. A criança aprende através da brincadeira, do movimento e da troca a partir do contato com outras crianças. Assim, ela copia e recria o mundo em que vive, transfere e modifica o conhecimento que adquire (KRAMER, 2009 apud BRASIL 2018b, p. 5).

E ainda ampliando o campo de possibilidades no trabalho com os anos iniciais, a orientação segue dizendo que é imprescindivel que o professor seja mediador de experiências que prezem as práticas de expressões culturais e artísticas, de modo a valorizar as múltiplas linguagens, como a música, a pintura, a espontaneidade, a poesia, o cinema, as narrações, as poesias, os cordéis, entre outras expressões artísticas culturais que promovem a continuação para a passagem da educação infantil. 
Os momentos de brincadeira também devem ocorrer sem a intervenção do adulto, entretanto, cabe ao professor o papel de mediador nas experiências vividas pelas crianças em instituições, nas diversas práticas de expressão cultural e artística e também nas múltiplas linguagens como a música, a dança, a poesia, o cinema, a pintura, o teatro, textos narrados, escritos ou dramatizados. Tais experiências devem ser prazerosas e geradoras de possiveis continuidades na passagem ao Ensino Fundamental (KRAMER 2009 apud BRASIL, 2018b, p. 5).

Diante do exposto, é evidente que as brincadeiras e as interações são essenciais para o bom desenvolvimento das crianças, estando elas na educação infantil ou no ensino fundamental. Isso também é notório ao analisar os documentos oficiais apresentados pelo governo federal na iminência de implementar políticas públicas que fortaleçam e favoreçam essas práticas. Compreendemos que a aprendizagem articulada às brincadeiras, à ludicidade, torna-se inevitavelmente prazerosa e divertida para a criança, enquanto para o professor é uma grande estratégia para o processo de ensino-aprendizagem.

Durante os relatos de momentos vividos na turma do primeiro ano, a ânsia pelo brincar e pelo movimento é constante. A inquietação para saber qual é o dia de brincar, qual é a hora de brincar e qual será o dia do brinquedo fica evidente e aflora diária e incansavelmente. Se acreditamos que a infância é uma fase que vai além de um momento da vida delimitado por documentos oficiais, precisamos permitir que as crianças possam viver e construir suas infâncias aprendendo principalmente por meio das brincadeiras, interações e materialidades. Afirmamos que as crianças são produtoras de cultura, e as DCNEI nos dizem isso também. No entanto, entregam-se livros didáticos para colorir e traçar letras, e colamos atividades xerocopiadas em seus cadernos de tarefa. "Pode isso, produção?", como se diz popularmente.

A vida infantil é um tempo precioso, e às vezes temos a impressão de que alguns a consideram somente até os 5 anos de idade, que é quando vivem de "ar" na educação infantil.

\section{CONSIDERAÇÕES FINAIS}

Respeitar a especificidade do seu momento de vida infantil significa preservar seu modo poético de abarcar o vivido, sua maneira imediata e lúdica de enfrentar o mundo e a si mesmo. Implica considerar pedagogicamente o modo singular de cada criança no seu encontro com o mundo, maravilhando-se ou horrorizando-se, criando e inventando significados que ultrapassam o sentido único, no desafio de conhecer a si própria no ato de imaginar, interpretar, e construir realidades. 0 modo poético é como a criança expressa seu jeito simultaneamente particular e universal de ser e estar no mundo, seu jeito de falar do mundo como uma maneira de falar de si (RICHTER, 2008, p. 32). 
Richter (2008) nos convida a refletir, a partir desse pequeno fragmento de sua obra e sob uma perspectiva poética, o momento da vida infantil. É possivel pensar como as crianças são seres ao mesmo tempo pequenos em estatura e grandes em capacidades e potencialidades. Uma vez instigadas e provocadas a vivenciar novas experiências, elas nos surpreendem com seu dinamismo, sua curiosidade e inventividade para demonstrar quem são, como são, o que pensam e como pensam, só precisam de uma única oportunidade.

Acreditar nas crianças e ouvir o que elas têm a nos dizer seria um bom caminho para que as vozes infantis sejam evidenciadas e possamos diminuir as lacunas entre as etapas de ensino da educação infantil e do ensino fundamental. A fala sempre foi algo negado às crianças. Muitos cresceram em lares em que as crianças não tinham o direito de se expressar por meio da linguagem oral. "Menina, você é a última que fala e a primeira que apanha!" Quem nunca ouviu essa frase em momentos em que os adultos discutiam assuntos de família?

Embora muito tenha se avançado nos estudos a respeito dos direitos das crianças e da garantia deles, muitas crianças ainda são privadas de desfrutá-los e sofrem com a negação de sua existência ocupando lugares de coadjuvantes na sociedade. De acordo com Abramowicz (2011, p. 24): "A fala da criança é uma inversão nos processos de subalternização, é um movimento político. [...] a criança falar não é pouca coisa".

Falar é uma das caracteristicas marcantes da infância. Então, por que não deixá-las falar? Seria interessante ouvir o que as crianças pensam sobre estudar em outra escola, se sentem falta de fazer algo que faziam na educação infantil, do que mais gostam na escola de ensino fundamental e do que não gostam tanto, como gostariam que a escola fosse, entre outras coisas que possam ajudar a escola a criar novas possibilidades de acolhê-las no início do ano letivo: "o desafio é o de ouvir no que têm para nos dizer e o de as escutar, isto é, tornar suas falas centro de compreensão dos contextos educativos e da sua transformação" (OLIVEIRA-FORMOSINHO, 2008, p. 70).

Infância é lugar de falar. Para Bueno (2018), infância é lugar de descobertas, que precisa de espaço, que gosta de miudezas, que precisamos vê-la como possibilidade de transformarmos o que nos acontece em experiências, que precisa estar com disposição atenta ao mundo, que é tempo de invenções. De acordo com Bueno (2018, p. 17):

Se a infância é uma relação, uma forma de ser e estar no mundo, pode nunca acabar. Um adulto capaz de reinventar uma relação, um adulto criador de ideias e conceitos, apaixonado pelo miúdo dessa vida, encantado pelas descobertas do aprender, é um adulto conectado com a potência da infância. E um adulto que encara seus desafios, encara a dor, a frustração, o medo e as incertezas e consegue aprender com eles, também é um adulto conectado à infância. 
É preciso colocar em prática tudo o que os documentos oficiais e os teóricos vêm trazendo e discutindo sobre a importância das construções e relações que o momento da vida infantil proporciona. Propiciar e preservar as ações inerentes à infância na educação infantil e no ensino fundamental é extremamente essencial. Valorizar e potencializar essas experiências permitirá que as crianças vivam intensamente e aprendam de maneira prazerosa e significativa.

Por fim, importa ressaltar que se faz necessário avançar nas pesquisas e aprofundar os estudos sobre o momento de passagem das crianças da educação infantil para o ensino fundamental e como elas vivenciam essa trajetória. Acompanhar turmas de pré-escola e posteriormente o primeiro ano seria interessante sob a ótica de analisar os sentimentos, os medos, as ansiedades, as alegrias; enfim, todos os sentimentos inerentes à infância ao se depararem com o novo e o diferente.

A criança sempre existiu e sempre vai existir. A infância também existe e existirá sempre. Poder-se-ia perguntar: que criança/s? Que infância/s? Sabe-se, todavia, que a forma de vivenciá-la/s (infância/as) tem e vem sofrendo mudança ao longo dos tempos, a considerar que esta/s criança/s, no processo de formação, enquanto ser no mundo, transforma e é transformada (PERIPOLLI; PASUCH; ZOIA, 2018, p. 78).

\section{Meetings and discontinues in the change of childhood education for fundamental education}

Abstract: The result of a theoretical research, which analyzes the transition of children from early childhood education to primary education. The objective is to expand the understanding mainly of the concepts of childhood, child and others referenced by early childhood education for elementary school. At the current juncture, it is essential to think and reflect on what childhood, the child and their transforming role in the world they face is. Concomitantly we will deal with what the legal documents say about it and what is the place of childhood in the early years of elementary school. We invite the reader to take a new look at childhood and the actions that it allows us to perform. We are supported by authors such as Richter (2008), Peripolli, Pasuch e Zoia (2018), Corsaro (2011), Kramer (2006), Bueno (2018), Brasil (2018a, 2018b), Oliveira-Formosinho (2008) among others.

Keywords: Childhood. Child. Play. Experiences. Moving from early childhood education to primary education.

\section{REFERÊNCIAS}

ABRAMOWICZ, A. A pesquisa com crianças em infâncias e a sociologia da infância. In: FARIA, A. L. G.; FINCO, D. (org.). Sociologia da infância no Brasil. Campinas: Autores Associados, 2011. (Coleção Polêmicas do Nosso Tempo, v. 102). 
ARIĖS, P. História social da criança e da familia. 2. ed. Rio de Janeiro: LTC, 1981.

BENJAMIN, W. Reflexões sobre a criança, o brinquedo e a educação. São Paulo: Summus, 1984.

BRASIL. Lei n. 8.069, de 13 de julho de 1990. Dispõe sobre o Estatuto da Criança e do Adolescente e dá outras providências. Diário Oficial [da] República Federativa do Brasil, Brasília, 16 jul. 1990. Disponivel em: http://www.planalto.gov.br/ccivil_03/leis//8069compilado.htm. Acesso em: 23 jul. 2020.

BRASIL. Referencial curricular nacional para a educação infantil. Brasilia: Ministério da Educação e do Desporto, Secretaria de Educação Fundamental, 1998.

BRASIL. Parecer CNE/CEB n. 24/2004, de 15 de setembro de 2004. Estudos visando ao estabelecimento de normas nacionais para a ampliação do Ensino Fundamental para nove anos de duração. Brasilia, 15 set. 2004.

BRASIL. Lei n. 11.274/06, de 6 de fevereiro de 2006. Altera a redação dos arts. 29, 30, 32 e 87 da Lei n. 9.394, de 20 de dezembro de 1996, que estabelece as diretrizes e bases da educação nacional, dispondo sobre a duração de 9 (nove) anos para o ensino fundamental, com matrícula obrigatória a partir dos 6 (seis) anos de idade. Brasilia, 2006. Disponivel em: http://www. planalto.gov.br/ccivil_03/_ato2004-2006/2006/lei//11274.htm. Acesso em: 20 jul. 2020.

BRASIL. Resolução CNE/CEB n. 5, de 17 de dezembro de 2009. Fixa as Diretrizes Curriculares Nacionais para a Educação Infantil. Brasilia, 2010.

BRASIL. Documento de referência curricular para Mato Grosso: educação infantil. 2018a. Disponivel em: https://drive.google.com/file/d/1e5kVi-RChfo5Zrt0r_Zf6SdliQ3YgIIL/view. Acesso em: 25 jul. 2020.

BRASIL. Documento de referência curricular para Mato Grosso: ensino fundamental - anos iniciais. 2018b. Disponivel em: https://drive.google.com/file/d/1z9YmiOIRBNYpExIK6yfACoA99wvKcW/view. Acesso em: 25 jul. 2020.

BUENO, M. C. No chão da escola: por uma infância que voa. Cachoeira Paulista: Passarinho, 2018.

CORAZZA, S. M. Infância \&t educação: era uma vez... quer que conte outra vez? Petrópolis: Vozes, 2002.

CORSARO, W. A. Sociologia da infância. 2. ed. Porto Alegre: Artmed, 2011.

INSTITUTO BRASILEIRO DE GEOGRAFIA E ESTATÍSTICA (IBGE). Expectativa de vida dos brasileiros aumenta 3 meses e chega a 76,6 anos em 2019. 2020. Disponivel em: https://agenciadenoticias.ibge.gov.br/agencia-noticias/2012-agencia-de-noticias/noticias/29505-expectativa- 
de-vida-dos-brasileiros-aumenta-3-meses-e-chega-a-76-6-anos-em-2019. Acesso em: 7 fev. 2021.

KRAMER, S. A política do pré-escolar no Brasil: a arte do disfarce. 8. ed. São Paulo: Cortez, 2006.

OLIVEIRA-FORMOSINHO, J. Escutar as vozes das crianças como meio de (re)construção de conhecimento acerca da infância: algumas implicações metodológicas. In: OLIVEIRA-FORMOSINHO, J. (org.). A escola vista pelas crianças. Porto: Porto, 2008.

PERIPOLLI, O. J.; PASUCH, J.; ZOIA, A. (org.). Infâncias na diversidade latino-americana. Curitiba: CVR, 2018.

RICHTER, S. Criança e pintura: ação e paixão do conhecer. Porto Alegre: Mediação, 2008.

RODRIGUES, S. A.; BORGES, T. F. P.; SILVA, A. S. da. "Com olhos de criança": a metodologia de pesquisa com crianças pequenas no cenário brasileiro. Nuances: Estudos sobre Educação, Presidente Prudente, v. 25, n. 2, p. 270-290, maio/ago. 2014. Disponível em: http://revista.fct. unesp.br/index.php/Nuances/article/view/3188. Acesso em: 22 jul. 2020.

Recebido em agosto de 2020. Aprovado em novembro de 2020. 